\title{
A Participatory Multiple Criteria Decision Analysis to Tackle a Complex Environmental Problem Involving Cultural Water Heritage and Nature
}

\author{
Otto Chen * ${ }^{(\mathbb{D}}$ and Dawei Han \\ Department of Civil Engineering, University of Bristol, Bristol BS8 1TR, UK; d.han@bristol.ac.uk \\ * Correspondence: otto.chen@bristol.ac.uk; Tel.: +44-117-903-5428
}

Received: 19 September 2018; Accepted: 1 December 2018; Published: 5 December 2018

\begin{abstract}
Multiple criteria decision analysis (MCDA) methods have shown advantages in supporting decision-making with problems that confront conflicting objectives. However, current applications to complex environmental problems featuring the dynamic social sphere, particularly problems involving cultural heritage and nature, have yet to substantially reflect this. The dynamic social sphere reflects the demand for scenario forecasting in decision-making support. This knowledge gap has not been addressed sufficiently in MCDA research. A participatory MCDA method is hence proposed as a merger with Contingent Valuation Method (CVM) as the scenario forecasting. The MCDA is then carried out to tackle a complex environmental problem caused by traditional food production in a historic town, Daxi in Taiwan. The result reveals a remarkable willingness to support this issue of a historically significant industry causing detriment to environment (with WTP estimate of 128,700,000 USD from the public) and suggests a plan that applies multiple policy instruments rather than following a potentially adverse polluter-pays principle. This manifests the authors' argument that recognition of heritage significance has dramatically affected selection of policy instruments and provides a critical recommendation to the local government which has struggled to find solutions. The proposed MCDA also highlights its participatory aspect for addressing issues involving cultural heritage, supported by several key steps, in particular the intervention-impact value tree building, the scenario forecasting and the sensitivity analysis.
\end{abstract}

Keywords: payment card method; policy instruments; polluter pays principle; resilience; scenario forecasting; stated preference technique; sustainability

\section{Introduction}

Multiple criteria decision analysis (MCDA) has been developed rapidly over the past quarter century with a variety of theories and models. Its capability to deal with multiple objectives or assessment criteria makes MCDA an ideal method to tackle environmental issues [1,2]. However, as there emerge more and more complex environmental problems featuring dynamic characteristics, namely the unknown responses of society and policy recipients, towards the implementation of policy [3], without some proper adaptions it appears impractical to employ MCDA in these cases. Unlike 'static' problems that dominate existing MCDA literature [4,5]; such as ranking sites, plans and products with the assessment of criteria based on known conditions of facts or of something happened (e.g., cost, size, age, distance, functionality and accessibility, etc.); dynamic problems usually involve policy instruments that need to be assessed (i.e., scoring) based on future outcomes (what we refer to as the scenarios of this research) to be logically forecasted and agreed before the policy instruments are chosen and implemented. Lack of confidence, or not being able to predict the impacts on society and the recipients of proposed policies or alternatives, is the main challenge and obstacle to the application 
of MCDA to dynamic problems. How to apply MCDA to dynamic problems with scenario forecasting has yet to be demonstrated in the real world, which reveals a significant knowledge gap and is therefore the focus of this research.

The application of scenario analysis approach in management research has also increased dramatically in the last two decades; it generally develops methods to plan for the future, including scenario planning, scenario building, scenario forecasting, development scenario, foresight and future studies. Analysing and studying events that may materialise enables the organisation to understand the environment and how it develops over time, so preparing in advance for a scenario that may become real [6]. This feature gives rise to a new set of approaches in decision-making support, which includes an integration of scenario analysis and MCDA. With regards to this integration, most of the literature focuses on developing methods or frameworks for planning or building scenarios systematically and comprehensively in MCDA cases, rather than focusing on developing methods of forecasting towards future scenarios (for details please see [6-8]); the knowledge gap mentioned previously.

Within the MCDA field, tackling complex environmental problems involving dynamic unknowns includes not only future impacts and outcomes of the policy instruments but also the environmental change perceived by people, particularly in economic valuation, as it facilitates assessment. Some researchers have therefore recommended employing economic valuation methods along with MCDA, especially when addressing the opinion and response of the public towards environmental change in monetary value [9-11]. However, there is scant literature illustrating this recommendation. Zoppi's article seems to be the only example [12] that applies an economic valuation method-the contingent valuation method-to derive the relations between willingness to pay (WTP) and the dependent parameters that are to be used as the criteria in MCDA, namely for acquiring the preference of the criteria (i.e., weights) from the public. After the criteria weights being derived from the contingent valuation method, the weights then become an input into the analytic hierarchy process (AHP) method developed to yield the ranking result. In other words, deriving the weights from the opinion of the public by the economic valuation method is the highlight of the integrated MCDA method proposed. The article clearly presents the importance of the two unknowns-future outcome (i.e., scenario) and the economic valuation of environmental change-in dynamic environmental problems. Our research focuses on how to employ economic valuation method as scenario forecasting, which involves both of these unknowns and how to integrate the scenario forecasting approach into a MCDA method developed with participatory advantages for dealing with conflicts, so that the participants of the decision-making with conflicting opinions are better supported with the critical information (in economic valuation) that they need to proceed with the MCDA, particularly with a coherent preview of the scenarios. Scenario forecasting featuring public engagement and coherent preview is one of the participatory advantages highlighted.

Heritage conservation has often faced incompatibility with urban development and sometimes with environmental protection; all are of great importance. An environmental problem involving heritage can encompass conflicting stakeholders such as the historical community, the public, local authority, experts, NGOs and so forth. Representation of conflicting circumstance and multiple objectives in MCDA might be expected in these instances. Scrutinization of the literature review in heritage studies, however, shows that application of MCDA method in heritage management is much less than MCDA application in other fields (e.g., transportation planning, energy planning and land use planning); there is little literature existing. Ferretti et al.'s article summaries thirteen MCDA applications in heritage studies [4]. Amongst thirteen papers summarised plus two papers written by Ferretti et al., fifteen in total, there are seven papers using MCDA for site ranking [4,5,13-17], six using MCDA + GIS for site ranking by mapping [18-23], one using MCDA for acquiring management priorities (i.e., importance of criteria) for ecosystem services [24] and one using MCDA for plan ranking in a given area [25]. All of them are applying criteria with known information, which means none of them deal with dynamic problems or involves unknown scenarios, regardless of a high inclusion of heritage management. This reflects the knowledge gap mentioned in other fields applying MCDA. 
Amongst the fifteen papers, there is one using monetary cost as a criterion of MCDA [5] and not any using utility or benefit as a criterion. This neglect of using utility or benefit as a criterion is also common in other fields applying MCDA, which does imply an inadequate selection of criteria. As any plan and policy instrument is considered an intervention, any notable impact caused by it, advantageous (e.g., utility and benefit) or disadvantageous (e.g., cost), should be selected as criteria in MCDA; however, the concept of impact and intervention in heritage management is narrow and in need of improvement [26]. Heritage conservation is dominated by values-based perspective; this has led to a tendency to regard value as the only respect needed for assessing changes and impacts caused by interventions [27,28]; also revealing the inadequacy of consideration towards impacts. Through the integration of an intervention-oriented perspective (proposed by the authors in previous research) and the concept of cost-utility into the value tree building of MCDA, the authors intend to reduce the knowledge gap of impact assessment in MCDA application and the scholarship of heritage studies. The value tree building approach can also assist communication between different experts (e.g., heritage, planning and environment practitioners), so as to acquire a more comprehensive consideration and performance of MCDA. It can also help heritage management practice catch up with the notable trend of the past two decades in heritage studies that shifts from a focus on physical preservation to a more inclusive view that underlines social significance and considers heritage as a continuing social process [28-32]. The authors hope the research can benefit the future applications of decision-making support involving heritage related dynamic problems that are expected to increase in the future.

The research intends to find out: (1) how does the scenario forecasting play an important role in applying MCDA to selecting policy instruments in complex environmental problems? And, (2) how to use a participatory method integrated with scenario forecasting to enhance public engagement and stakeholder participation, so as to obtain adequate policy instrument, particularly for achieving multiple objectives-protecting nature, cultural heritage and society? A complex environmental problem, a heritage food production in Daxi, Taiwan, hence is investigated, which involves conflicting stakeholders and the two aforementioned unknowns that make the environmental issue a dilemma for local government. As people might yield different views and attitudes towards the pollution issue once a traditional food production is deemed as a cultural heritage, through this case study the research also intends to help tackle the issue by exploring (3) is Daxi togan production deemed as cultural heritage by Taiwanese people? And if so, how does the recognition of cultural heritage affect the idea of the polluter-pays principle in selecting policy instruments? It is expected the findings will also help underline the social significance of cultural heritage in both heritage and environmental studies.

\section{Materials and Methods}

\subsection{Case Study}

Daxi is a district in eastern Taoyuan City in northern Taiwan (Figure 1), voted by Taiwanese people as the best small tourist town of Taiwan in 2012. The town is popular for abundant cultural heritage and scenic spots. The cultural heritage features the diversity of early modern history in Taiwan, encompassing Taiwanese Plains Indigenous Peoples, Taiwanese people, (i.e., Han Chinese immigrated from China in 18th century) and Japanese colonialism (between 1895 and 1945 Taiwan was under Japanese rule) (Figure 2); geographically, it represents the earliest history of the Han Chinese migrating to the upstream area of the Tamsui River catchment (the Dahan River). Mausoleums of the two most famous presidents, Chiang Kai-shek and Chiang Ching-Kuo, (Cihu Mausoleum and Touliao Mausoleum) are located here, as both presidents considered this place significant. The town covers the upstream part of the Dahan River. There are two water resource conservation areas-Shihmen Reservoir and Bansin. Shihmen Reservoir was built upstream at southern Daxi in 1964, the biggest in East Asia, considered the most important catchment in Taiwan at the time. 


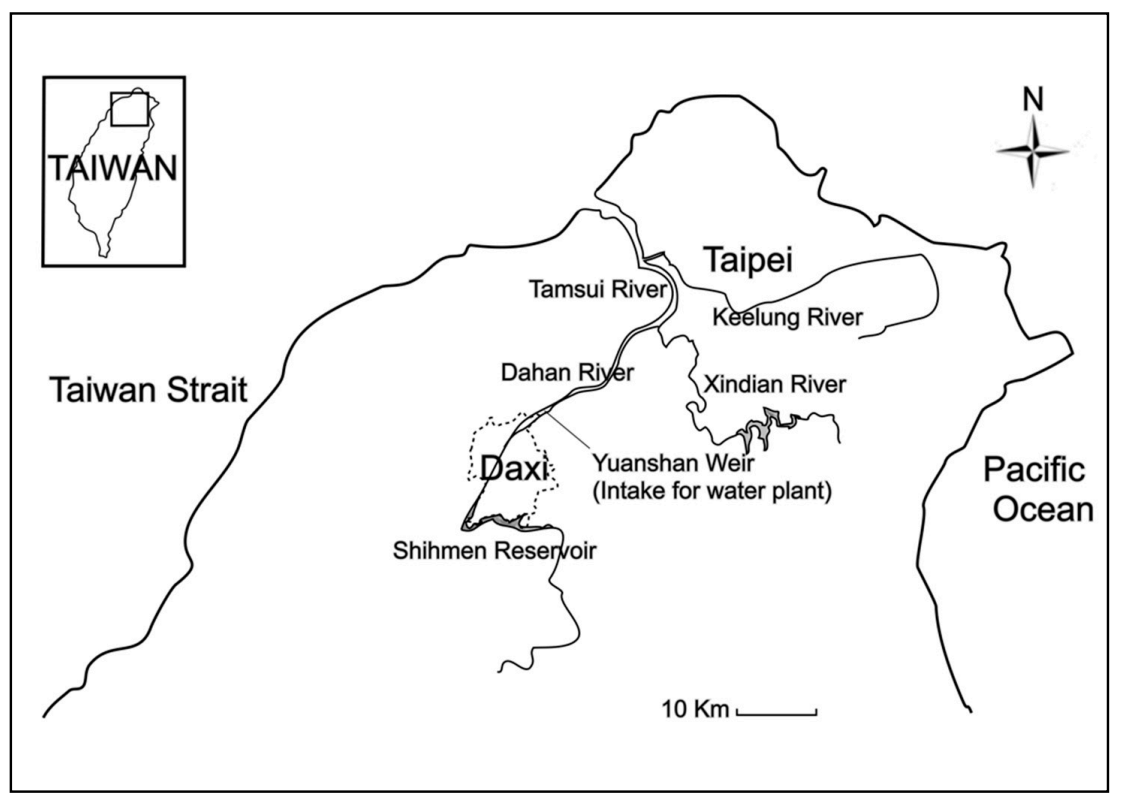

Figure 1. The map of Daxi and the Dahan River.

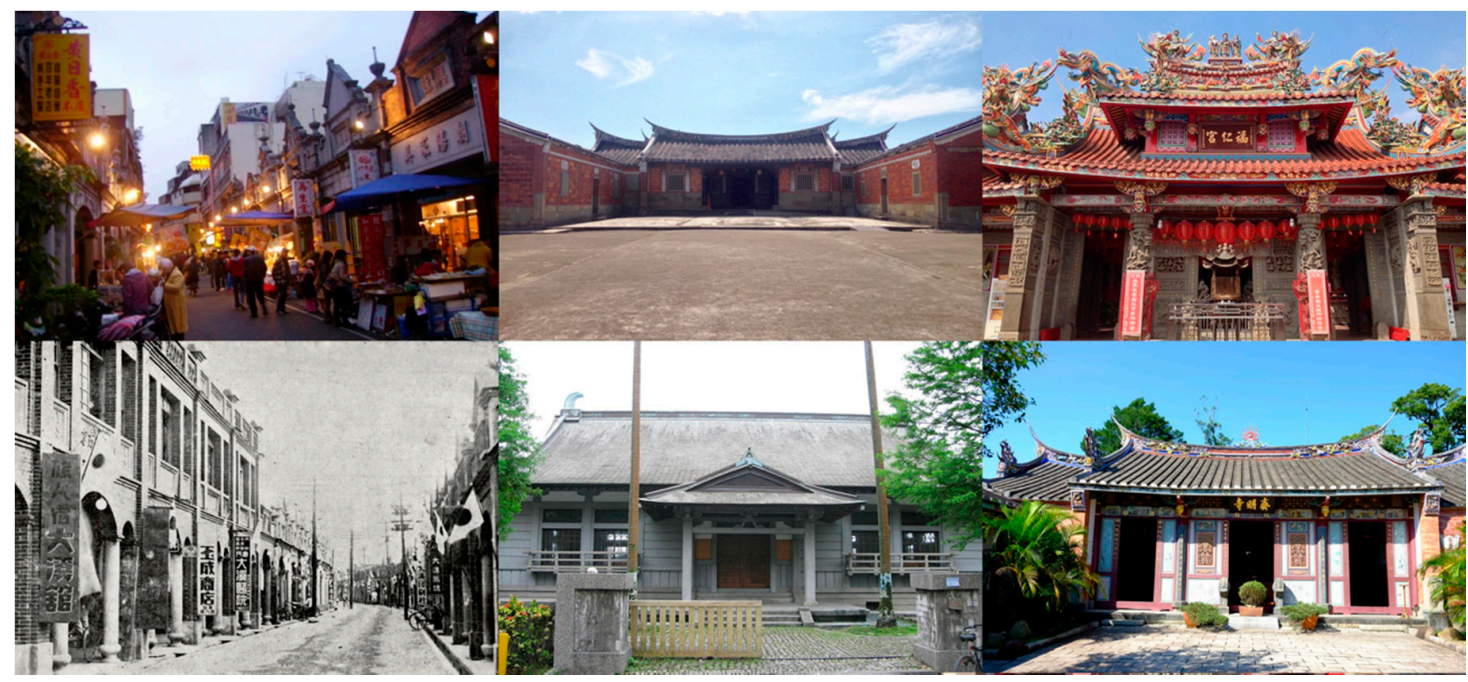

Figure 2. Cultural heritage of Daxi. Source: Based on Wikimedia Commons. Legend: Upper left shows the present Daxi Old Street, where the sale of togan is the dominant activity of the town; lower left shows the same street in Japanese colony period, implies the historic character of the town; upper middle: the Lee Teng-fan's Ancient Residence; lower middle: Japanese historical architecture Daxi Wude Hall; upper right: Daxi Furen Temple; lower right: Daxi Zhaiming Temple.

The focus of this research is another important contributor to heritage and popularity, namely the production of togan (i.e., dried tofu, Figure 3). Togan, a traditional food of the Tang Dynasty Han Chinese, dating back over 1200 years, is cultivated by coagulating soy milk and pressing the resulting curds into firm, dry blocks; water plays a key role in production. Not every traditional food is considered cultural heritage; only when it is considered significant towards the development of a given place and represents a special interaction between human and environment. Only a few togan productions in the areas of the Han Chinese are considered cultural heritage. Most of them share the benefit of outstanding spring water. The production of togan in an area with outstanding water and historical link represents a specific lifestyle of people who have adapted to particular environmental conditions and made use of these to make a living. Daxi togan's unique recipe also increased preservability, an advantage in a time without refrigeration. Development of the Daxi 
togan industry reflects the history of the Han Chinese immigration to an indigenous area, which subsequently developed into the trade centre of the Dahan River in the Japanese colonial period. Therefore, Daxi togan is considered as cultural heritage by Taiwanese people and has become an important industry in Taoyuan City. Sales of Daxi togan are estimated in excess of 330 million US dollar per year [33] (all original estimates are converted into US dollars using the following exchange rates (April 2018): 1 USD = 29.5 TWD, with no adjustment for economic growth).

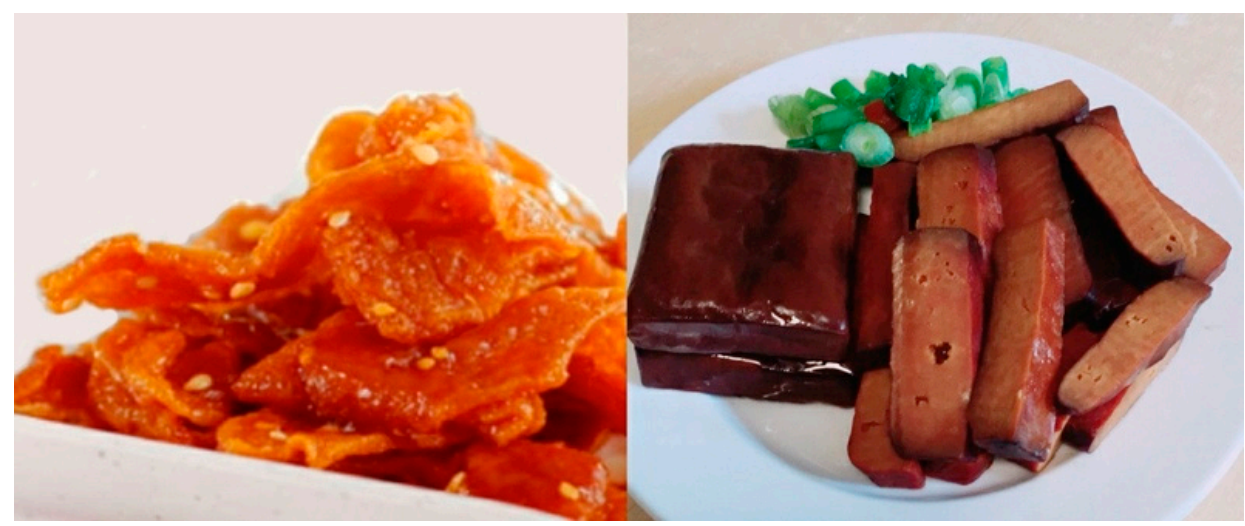

Figure 3. Typical Daxi togan (right) and togan made as a snack (left). Source: Authors.

Water and soybean are the two main materials for making togan. The production of $1 \mathrm{~kg}$ togan produces approximately $3.25 \mathrm{~kg}$ wastewater. The disposed liquid is similar to soymilk, basically edible and nontoxic but a large amount of untreated waste liquid can cause serious water pollution. Pollution caused by production of Daxi togan is the environmental issue this paper intends to tackle.

Togan began as a food made at home, for home consumption. Over the last century, a few Daxi families began to sell it. During Japanese rule, construction of traffic and irrigation infrastructures facilitated the development of industries here, consequently more families became manufacturers of togan. It was the agricultural era, most people lived near waterways, it was natural for them to use superior spring water to produce togan at their homesteads. Without a concept of pollution, wastewaters returned to the water system untreated. Production was small scale, so contamination was negligible. However the establishment of Cihu Mausoleum (1975) and Shihmen Reservoir, boosted tourism in Daxi, spreading the reputation of Daxi togan, leading to increased production and waste.

As togan sales rose, the associated pollution increasingly concerned local government. An intake for water treatment plants at Yuanshan Weir is only $2.5 \mathrm{~km}$ downstream of affected waterways. In December 2017, a backup reservoir started to operate only several hundred metres downstream of the polluted waterways. This reservoir supplies clean water to water treatment plants when torrential rain causes serious soil erosion in upstream Shihmen Reservoir, making the water too turbid to use [34]; revealing that there are a variety of ways of directly or indirectly affecting the sustainability of cultural heritage by climate change. Risk of taking polluted water into the backup reservoir has made this issue increasingly urgent.

There was historical background to non-intentional pollution caused by togan production in Daxi. Under statutory requirement in recent decades, to protect water for agricultural use, factories are no longer permitted to be set up by water sources. Generally, only large enterprises can afford the cost of wastewater treatment and there are no laws or regulations established for homebased businesses, so no requirement exists to control and manage wastewater discharge from unregistered togan factories. Unregistered kitchens are commonly disguised as homesteads. Conducting business in a grey area of statutory requirement has become normalised in the Daxi togan industry; reflecting conflicts between activities of cultural heritage, modern land use, modern statutory requirement and nature. Considering that togan production is recognised as a cultural heritage and the difficulties of production being legal in accordance with current laws, the local government does not want to ban or 
remove unregistered factories as they would to deal with other industrial polluters. How to tackle pollution without harming the togan industry has vexed local government.

National law prevents legalising existing unregistered togan factories without relocation. It is unacceptable to establish a new law, national or local, such as a home-business regulation for legalising existing unregistered togan factories without relocation, in order to demand wastewater treatment.

Treating the polluted water through the sewer system is not the answer either. Firstly, the coverage rate of the sewerage system is rather low $(40.6 \%$ in urban planning areas, $0 \%$ in non-urban planning areas) as it is still under construction. Secondly, more than half of togan factories are located in non-urban planning areas (e.g., farmland, woodland), where the sewer system is inaccessible. This situation has forced the local government to apply engineering means to intercept and purify the polluted streams; however, the treatment rate remains low. Contaminated waterways contain two main types of point source pollution: domestic wastewater and togan waste liquid. The local government currently uses low-cost treatment that treats low pollution domestic wastewater as the public may consider the high-cost treatment to remove industrial waste an illegitimate public expense. The government does not want to risk investment before it ascertains if the public is willing to pay and if so, how much they are willing to pay, to help with this problem.

The solution is likely to lie between the polluter-pays and government-pays principles, meaning the polluter will still pay costs to some extent, implying some adverse impacts to the industry. Therefore, aside from the challenges and unknowns aforementioned, impacts of possible policy instruments need to be previewed and estimated. These unknowns will be dealt with by the economic valuation method as scenario forecasting in the MCDA proposed in the next section.

\subsection{Study Design}

The MCDA method proposed in this paper mainly applies the Weighted Sum Model (WSM). It is the most understandable and transparent model in MCDA, particularly suitable for tackling decision-making problems involving conflicting stakeholders in terms of transparency and deliberation, as is the case in this research. The preference $P_{i}$ of alternative $A_{i}(i=1,2,3, \ldots, M)$ is calculated according to the following equation [35]:

$$
P_{i}=\sum_{j=1}^{N} a_{i j} w_{j}, \text { for } i=1,2,3, \ldots, M .
$$

Therefore, the best alternative is the one with the largest preference value. However, the scores (i.e., $a_{i j}$ ) must be numerical and standardised. Furthermore, the logical distribution of the weights (i.e., $w_{j}, j$ represents individual criterion) between conflicting aspects (e.g., heritage vs. natural environment) is critical, hence a pre-weighting process is recommended later in this article.

An intervention perspective for dealing with impact assessment in heritage management has been proposed by the authors in previous research; a matrix perspective highlighting a comprehensive consideration towards intervention recipient ensemble-heritage, context and nature, with three assessment aspects—value, sustainability and resilience (Figure 4). The intervention perspective provides a more comprehensive and inclusive way of thinking regarding impact assessment, as the current practice has a tendency of focusing on physical preservation; at most, consideration extends to the surroundings of the heritage (usually the aesthetic aspect of the setting) [28-32], ignoring that natural environment is an interdependent part of heritage ensemble. Values-based perspective is dominant in heritage conservation, solely using value aspect to assess intervention [27,28], leading to a narrow consideration regarding impact assessment [26]. Two additional assessment aspects, namely sustainability and resilience, are hence proposed by the authors to supplement the missing spheres of assessment; sustainability enhances temporal coverage, whilst resilience enhances probability and risk management. Although it is widely accepted that sustainability includes the economic sphere, implying an overlap with value aspect in the matrix, the value and sustainability aspect referred to here have different focuses towards impact assessment. In this case, doing nothing to the pollution 
(Plan A) and treating the pollution by government resource (Plan B) may not cause adverse impact on cost and sales (C3), whilst the public may have different views on these two plans, such as an irresponsible loss of reputation that affects sustainability. However, the resilience proposed refers to ability to recover from destructive loss or damage due to the impact of a change (e.g., policy), no matter how small a possibility; differing from the value aspect that is based on certainty and the present time.

As can be seen from Figure 4 (left), heritage contains the people living within it; and context includes the community living within the setting of heritage. The proposed intervention perspective particularly underscores the importance of people and social sphere in heritage management, in line with the most notable emerging trend in heritage studies [29], echoing a concerning inadequacy of social impact assessment in environmental protection [36,37]. Furthermore, applying the perspective to the proposed MCDA can help communication between heritage practitioners and other professionals (e.g., environmentalists), so as to help different stakeholders identify important impacts as assessment criteria. The authors hence transform the matrix into the value tree of MCDA, along with another important point-adding cost and benefit to the value aspects—for preventing ignorance of benefit/utility respect in MCDA application (Figure 5). The value tree proposed can therefore be applied as a framework particularly suitable for environmental problems involving cultural heritage and nature. It is also notable that the aim of the MCDA case is to achieve a 'harmonious environment,' protecting the natural environment whilst maintaining an advantageous societal environment for cultural heritage to survive and sustain.

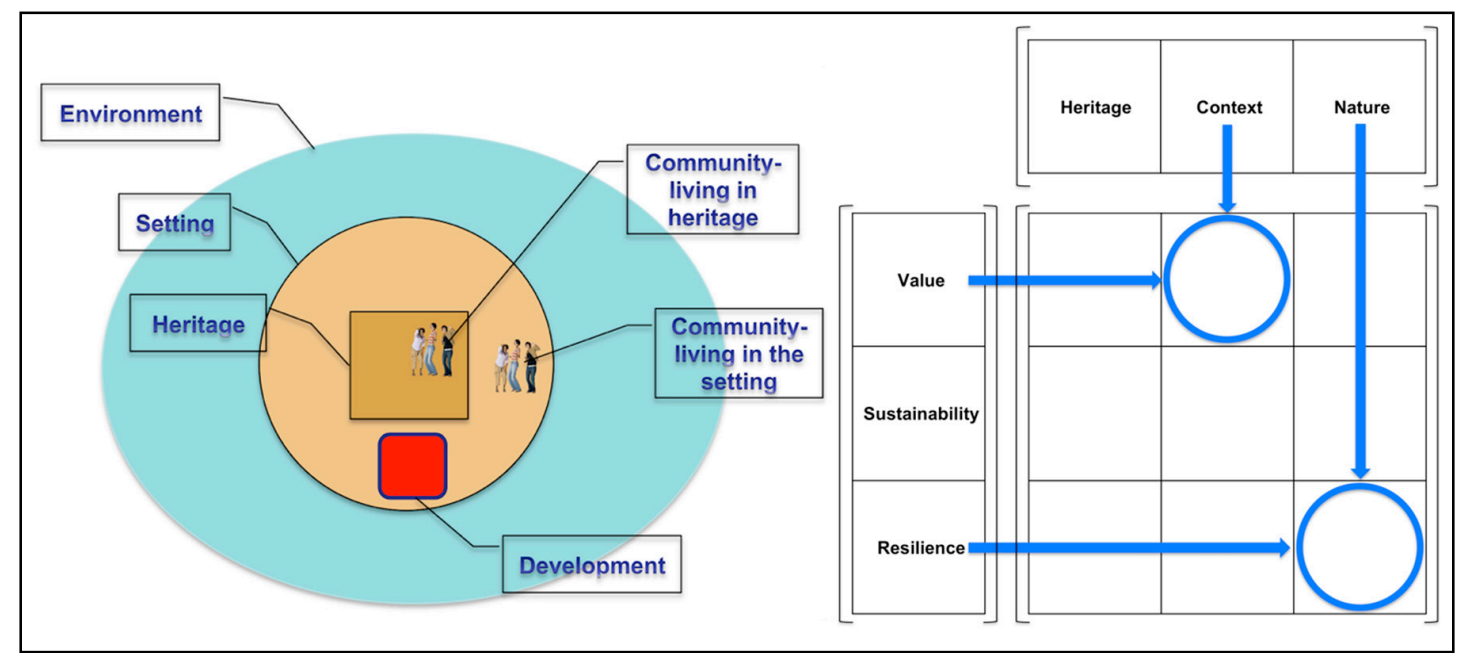

Figure 4. The intervention matrix perspective proposed by the authors in previous research.

As for proposing the plans/alternatives of MCDA, a systematic assessment regarding possible policy instruments is necessary; an advantageous process for proposing solutions in governance [38]. Since the environmental problem involves a cultural heritage, not merely a traditional food production, the local government is against applying strict measures of the polluter-pays principle [39], in order to avoid adverse effects to the togan industry. They are stuck for a solution because they have no idea to what extent the public will support this cultural heritage. Regardless of diversity in the classification and evaluation approach of policy instruments (details please see [40-45]), it is feasible that the solution of this case lies between government-pays and polluter-pays. Based on several on-site meetings for this pollution issue, attended by manufacturers, local representatives, experts and governors, the challenges and demands of the different stakeholders as well as the resources of the government are considered. The research hence proposes five plans, with four policy instruments, namely organisation-based, economic, regulatory and information-based instrument, as shown in Table 1. Each plan may be only one instrument applied, or multiple instruments applied. Four criteria are applied in the research to assess and select the policy instruments, including effectiveness, acceptability (to stakeholders and the public), economic feasibility and technical feasibility. 


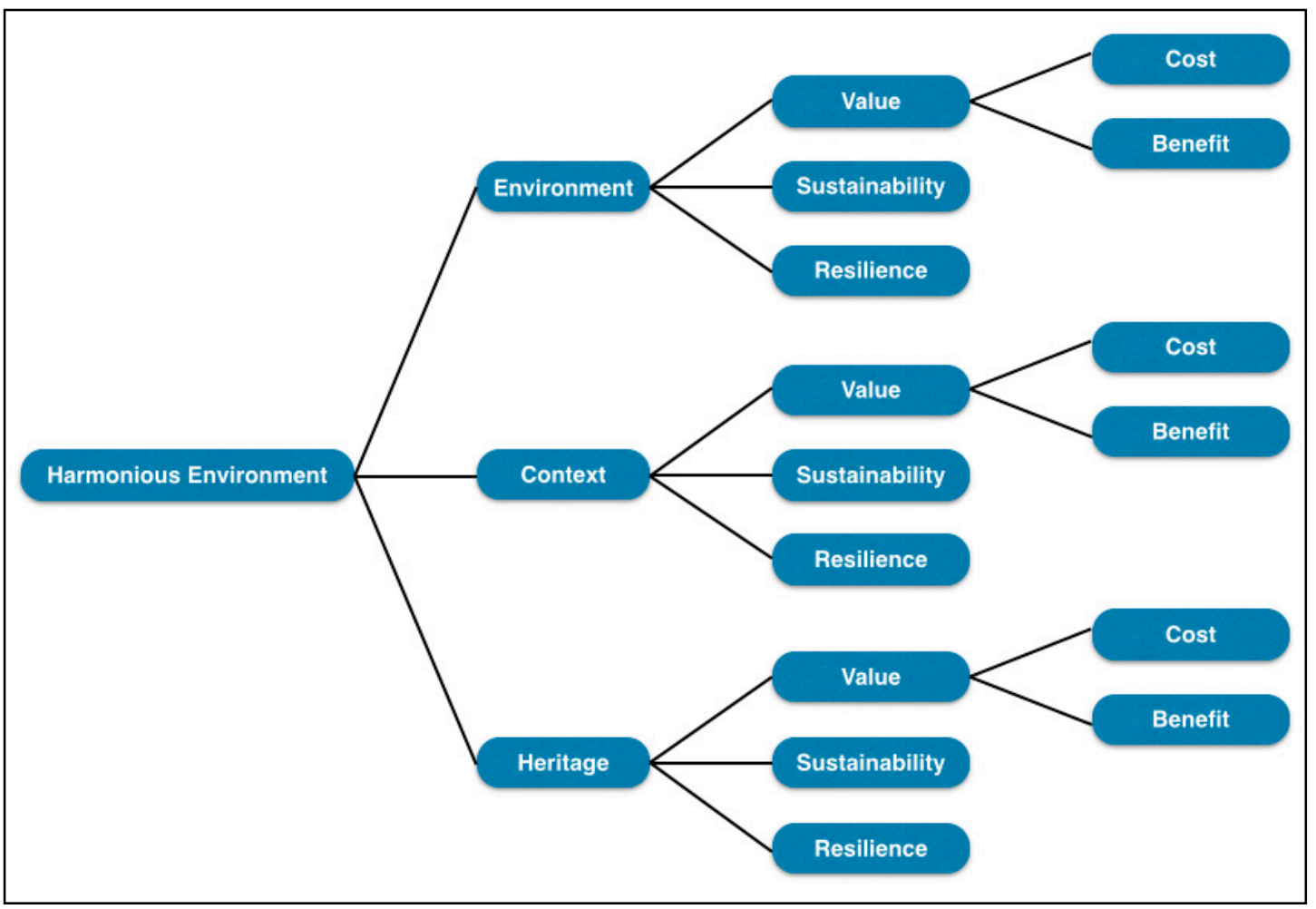

Figure 5. Value tree framework with the inclusive considerations transformed from the intervention perspective.

Considering the constraints of legality and historical background and that environment and heritage both are in need of protection, understandably the tools of government are limited. Plan A is the status quo (i.e., doing nothing except for moral suasion), mainly for the purpose of assuring the other four alternatives proposed are not worse than the status quo in all criteria, as unregistered factories are unlikely to be persuaded to treat the wastewater due to the cost of treatment. Plan B and Plan C are both on government-pays basis, with organisation-based policy instrument, which aims to intercept polluted water and purify it with treatment facilities built and supported by the government. The difference is that Plan B will implement the instrument within the financial limitation-the amount the public agree the government to spend-and Plan $C$ without considering the opinion of the public. The opinion of the public implies the togan industry is excused to some extent due to the status and background of cultural heritage. Plan $C$ has a risk of being challenged on social justice towards resource allocation. Plan D lies between government-pays and polluter-pays basis, with economic instrument-subsidy—to encourage legalisation (i.e., relocating factories), as well as regulatory instrument-ban or fine-to prohibit pollution discharge. Once the factory is legalised, which means it is registered and monitored, the factory needs to treat wastewater at its own cost. Plan E is purely on polluter-pays basis, with only regulatory instrument-ban or fine-to prohibit pollution discharge. Without any monetary support, it is the most challenging for the manufacturers.

As can be seen from Table 1, there exist some unknowns that need to be solved so as to proceed MCDA; an obstacle to government in proposing possible solutions. For Plan B and D, the maximum amount of government spend the public will allow for each plan needs to be known, otherwise the planners will not be able to propose specified plans in detail (i.e., technical); more importantly, the policy change might be unacceptable to the public, becoming a political disaster. For Plan D and E, the relationship between togan price and sales also should be acquired, so that the sales volume can be used as a MCDA criterion. Since additional cost of treatment and legalisation will reflect on price and sales, policy change is critical to the survival of this heritage. The scores of this critical criterion can be objectively estimated by scenario forecasting. 
Table 1. The proposal of the rough alternatives for MCDA and the additional information needed.

\begin{tabular}{|c|c|c|c|c|}
\hline & $\begin{array}{l}\text { Policy Instruments } \\
\text { Applied }\end{array}$ & Plan & Description & $\begin{array}{l}\text { Scenario Forecasting } \\
\text { Information Needed }\end{array}$ \\
\hline \multirow[t]{4}{*}{$\begin{array}{c}\text { Government-pays } \\
\uparrow\end{array}$} & Organisation-based & $\begin{array}{l}\text { C-Wastewater } \\
\text { treatment to a } \\
\text { high degree }\end{array}$ & $\begin{array}{l}\text { Intercept and treat wastewater from the } \\
\text { waterways, treating as much pollution } \\
\text { as possible, without considering the } \\
\text { opinion from the public. }\end{array}$ & \\
\hline & Organisation-based & $\begin{array}{c}\text { B-Wastewater } \\
\text { treatment }\end{array}$ & $\begin{array}{l}\text { Intercept and treat wastewater from the } \\
\text { waterways, within the financial } \\
\text { limitation (WPT) from the opinion of } \\
\text { the public. }\end{array}$ & $\begin{array}{l}\text { How much support- } \\
\text { willingness to pay (WPT) by } \\
\text { the taxpayers }\end{array}$ \\
\hline & $\begin{array}{l}\text { Economic \& } \\
\text { Regulatory }\end{array}$ & $\begin{array}{l}\text { D-Ban illegal } \\
\text { and provide } \\
\text { subsidy to } \\
\text { legalisation }\end{array}$ & $\begin{array}{l}\text { Ban illegal factories, whilst providing } \\
\text { subsidy to the legalisation of } \\
\text { manufacturers within the financial } \\
\text { limitation (WPT) from the public. The } \\
\text { polluters still need to pay the cost for } \\
\text { wastewater treatment. }\end{array}$ & $\begin{array}{l}\text { 1. How much } \\
\text { support-willingness to } \\
\text { pay (WPT) by } \\
\text { the taxpayers } \\
\text { 2. } \begin{array}{l}\text { How much } \\
\text { impact-sales volume } \\
\text { and price relationship }\end{array}\end{array}$ \\
\hline & Information-based & A-Status quo & Do nothing except for moral suasion. & \\
\hline $\begin{array}{c}\downarrow \\
\text { Polluter-pays }\end{array}$ & Regulatory & E-Ban illegal & $\begin{array}{l}\text { Ban illegal factories. The polluters need } \\
\text { to pay the costs of the legalisation and } \\
\text { wastewater treatment. }\end{array}$ & $\begin{array}{l}\text { How much impact-sales } \\
\text { volume and price } \\
\text { relationship }\end{array}$ \\
\hline
\end{tabular}

After proposing the five alternatives (Table 1), the criteria of MCDA can be elicited with the framework of the value tree (i.e., Figure 5) according to the impact of the five plans identified by different stakeholders. It can prevent blindness and bias of different stakeholders with regard to selecting criteria, particularly in conflicting circumstances. Moreover, as the future can never really be predicted, applying the intervention perspective helps to narrow down notable impacts (i.e., as criteria) of interventions (i.e., plans) to carry out scenario forecasting. Amongst the important impacts, there are six selected as the criteria; $\mathrm{C} 1-\mathrm{Cost}$ refers to the amount of money the government needs to spend on the given plan; C2-BOD refers to the pollution level after the given plan is implemented; C3-Sales refers to sales of Daxi's togan after the given plan is implemented; C4-Employment refers to the employment condition of local people; C5-Heritage Sustainability refers to sustainability of the heritage and heritage community; C6-Heritage Resilience refers to the ability of the heritage and heritage community to recover from a destructive loss (i.e., sales, reputation) due to the impact of the policy. The scoring of $\mathrm{C} 1$ and $\mathrm{C} 3$ relies on the scenario forecasting - the contingent valuation method (CVM); the scoring of $\mathrm{C} 2$ relies on the scores of $\mathrm{C} 1$ (i.e., budgets) to estimate the pollution level by planners from the technical details decided; the scoring of C4, $\mathrm{C} 5$ and $\mathrm{C} 6$ relies on the deliberation of stakeholders and experts to reflect the impacts of the plans, which is set to be scored from 0 to 10 .

After constructing the value tree with criteria, the next step of pre-weighting is suggested, as shown in Figure 6, as the proposed MCDA is prone to face biased criteria distribution pattern; a pre-weighting can effectively mitigate this issue. Stakeholders often end up eliciting a value tree with unbalanced criteria distribution in conflicting objectives, meaning the weights are not logically assigned. In this case (Figure 6), since there are three criteria $(\mathrm{C} 3, \mathrm{C} 5, \mathrm{C} 6)$ relating to heritage whilst there is only one criterion relating to environment (C2), without pre-weighting to obtain logical weights the result is prone to bias towards plans that benefit heritage-side stakeholders. The rules of pre-weighting include, start from left of the branches to the right to distribute weights; the first level of branches sum up in one and so do the last; the weights of each level are decided under the deliberation of stakeholders with the support of experts to obtain a logical distribution according to the condition of the given case. This pre-weighting process can effectively help stakeholders obtain an essential idea of relative importance between criteria before the influence of knowing the scores, so as to elicit logical formal weights after scoring. Even if a set of formal weights given by a stakeholder at a later stage are very different from the pre-weighting set of weights, the stakeholder then will be able to explain it to other conflicting stakeholders rather than utilising intuitive judgement or the intention to affect 
ranking. Furthermore, with the reference of pre-weighting, swing weights technique or other pairwise comparison methods can be applied if there are numerous criteria needing to be weighted.

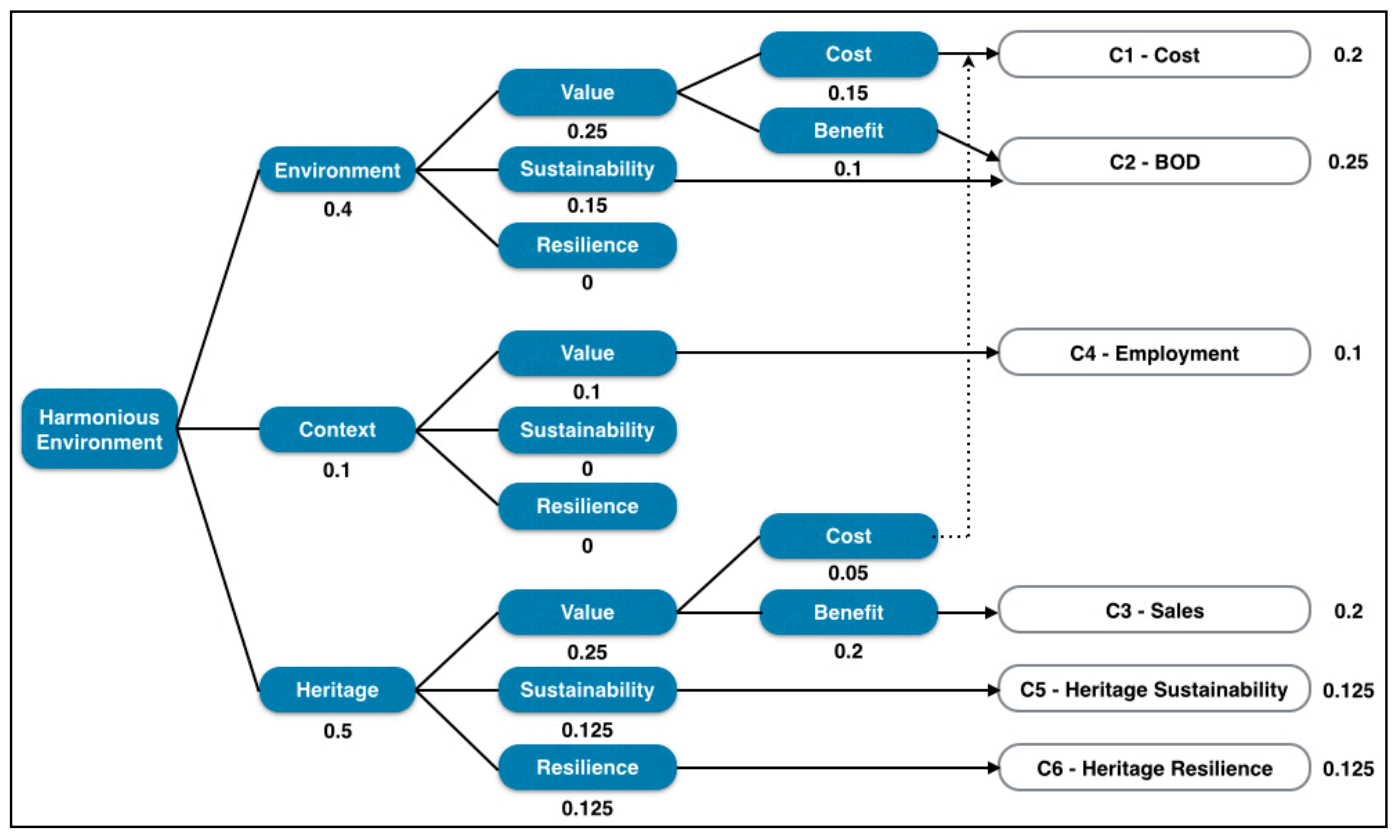

Figure 6. The criteria elicited and the pre-weighting. Legend: It must be noted that a criterion can consist of different sub-attributes (e.g., C1, C2), meaning the trade-off relation can exist at any level (e.g., C1: between heritage and environment; C2: between value, sustainability and resilience).

The monetary value of environmental changes can be assessed by eliciting the public's preferences for non-marketed goods without market price through a range of economic valuation methods. The stated preference methods (e.g., contingent valuation, choice experiment) employ the survey technique to elicit preferences and valuations from the general public [46]. Due to the nature of this environmental problem, this research applies the contingent valuation method (CVM) for scenario forecasting, with payment card method as the elicitation format. Payment card format uses an ordered set of threshold values that respondents are asked to peruse and indicate the highest amount they are willing to pay. There are other elicitation formats. Since every format is subject to some degree of bias (for details of other formats please see [46-48]), the advantages of selecting payment card method include avoidance of a non-response situation in open-ended (i.e., 'name the amount') format, avoidance of starting point bias [1,49], reduction of the number of outliers and respondents' effort $[46,50]$. Another important character is that the WTP estimates of the format are generally more conservative than those generated by other formats [51-53], which is most appropriate for this case with its budgetary considerations.

A CVM survey for scenario forecasting was conducted in April 2018 in Taiwan, following the demands in Table 1, for deriving (1) willingness to pay (WTP) to support cultural heritage and (2) the relationship between sales and price for estimating impact on industry. When a respondent selects a certain bid on the payment card, their true WTP will be between that number and the next number up. It means the intervals must be fine enough to obtain an accurate estimation, whilst also coarse enough to facilitate each respondent to decide which interval contains their actual willingness to pay $[50,54]$. Therefore, before the formal survey, a pre-test survey was conducted to test the bid range and understandability of the questionnaire. The final version of the questionnaire clearly defines income taxes as the payment vehicle for households, the timing of payment is defined as a yearly payment for five continuous years. The questionnaire is translated into English (originally in Chinese) and shown in Appendix A. 
For the method to calculate the WTP, the study applies a midpoint approach, which is based on Turnbull's lower bound mean estimate of WTP $[55,56]$. The lower bound mean (LBM) approach appeals to many policy makers as its estimates are more conservative and straightforward, this is calculated as follows:

$$
L B M=\pi_{0}\left(p_{0}\right)+\sum_{i=1}^{k} \pi_{i}\left(p_{i}-p_{i-1}\right)
$$

where the $\pi_{i}$ are percentages who are willing to pay a given amount $p_{i}$; the initial bid is $p_{0}$ and $k$ is the number of bids offered after the initial bid $p_{0}$. Instead of using lower bound, we use the midpoint of each interval. According to Kristrom [56,57], this adaption should be able to get a more realistic estimate, as follows:

$$
\begin{gathered}
\text { Midpoint Mean }=L B M+\frac{1}{2} p_{0}\left(1-\pi_{0}\right) \\
+\sum_{i=1}^{k} \frac{1}{2}\left|\pi_{i}-\pi_{i-1}\right|\left(p_{i}-p_{i-1}\right)+\pi_{k}\left(p^{*}-p_{k}\right)
\end{gathered}
$$

where $p^{*}$ is the average bid price provided by the respondents who are willing to pay the maximum bid of the range or more, which is used as midpoints of other intervals for calculation because there is no interval beyond the maximum bid given by the question.

As the proposed MCDA highlights participatory features, this article summarises the critical steps regarding participants and purposes (Table 2). Experts play a notable role in the MCDA. At the step of value tree building they help stakeholders identify important impacts with the support of the intervention framework proposed and select appropriate ones as criteria. Through pre-weighting, experts can further understand demands and considerations of stakeholders, so that they can better represent the stakeholders to complete formal weighting in the later stage. At the scoring step, experts need to assist the stakeholders to score in C4, C5 and C6, referring to the information obtained from scenario forecasting (i.e., C1 and C3). Notwithstanding there are several interest groups involved in the case, such as heritage community (the manufacturers), local community, water resource authority, planning authority and environment agency, through the understanding from pre-weighting, the research summarises the weighting patterns into three tendencies, namely environment, heritage and planning, each represented by at least one expert through the weighting process. Instead of directly reaching a set of weights through deliberation, as the pre-weighting does, the listing of the three sets of weights (Table 5) provides the decision maker with clearer sight of differences and provides necessary

\begin{tabular}{|c|c|c|}
\hline Step & External Participants & Purpose \\
\hline Scenario forecasting & The public/policy recipients & $\begin{array}{l}\text { To provide necessary information for proposing solution plans and } \\
\text { proceeding MCDA, as well as to deliberate the matter of resource allocation } \\
\text { with conflicting stakeholders and the public }\end{array}$ \\
\hline Weighting & $\begin{array}{l}\text { Experts representing } \\
\text { stakeholders }\end{array}$ & $\begin{array}{l}\text { To include opinions of conflicting groups so as to better achieve multiple } \\
\text { objectives }\end{array}$ \\
\hline Scaling & Stakeholders with experts & To show the better way of scaling with transparency to the stakeholders \\
\hline Sensitivity analysis & Stakeholders with experts & $\begin{array}{l}\text { To explain the selected final solution by sensitivity analysis with } \\
\text { transparency to the stakeholders }\end{array}$ \\
\hline
\end{tabular}
information for the sensitivity analysis process.

Table 2. The summary of participatory features.

\section{Results}

Estimation of WTP usually yields median and mean WTP. The research chooses median WTP as the scenario forecasting for the scoring of C1-cost. The WTP estimate represents the amount of money the public allows the government to spend, supporting cultural heritage to deal with pollution. 
The median WTP is chosen mainly for three reasons. Firstly, as WTP is to be considered as a government budget for tackling the pollution issue, implying a majority voting rule basis, the median WTP represents there being $50 \%$ of people willing to pay more [46], which matches the voting rule. Secondly, the median WTP is usually less than the mean WTP in most cases [46,50]; a conservative estimate is appreciated from the viewpoint of governmental budget. Thirdly, the median WTP is generally less affected by other factors, such as different estimation approaches once applied (e.g., ordinary least squares (OLS) or maximum likelihood (ML), although both are not used in the research), by embedding effects (the higher WTP given because the respondent considers the price as for all conservation projects of the country) [58] and by illogical value answers beyond the maximum threshold value.

The formal survey collected 272 effective questionnaires through an online survey platform $(100 \%$ response rate). The profile of survey respondents is as follows. There were more females than males (68.7\% and $31.3 \%$, respectively). The majority $(90.8 \%)$ were graduates of university and higher degrees, followed by $9.2 \%$ with qualifications from senior high school and lower degrees. The age distribution was: the majority (46.7\%) were 40-49 years old, followed by $30-39$ years (26.5\%), 50-59 years $(15.1 \%)$, $20-29$ years $(7.0 \%)$, more than 60 years old $(4.4 \%)$ and 19 years and younger $(0.4 \%)$. Average annual household income for the majority of respondents (30.5\%) was NT\$500,000-1,000,000, followed by NT\$1,000,000-1,500,000 (29.4\%), NT\$2,000,000 and more (18.8\%), NT\$1,500,000-2,000,000 (14.3\%) and NT $\$ 0-500,000$ (7\%). Number of people per household for the majority $(31.6 \%)$ was four members, followed by three members $(21 \%)$, five members $(19.9 \%)$, two members $(11.4 \%)$, six members and more $(11 \%)$ and only one member (5.1\%). Distribution of residence was: northern Taiwan (68.4\%), southern Taiwan (23.5\%), central Taiwan (5.9\%), eastern Taiwan (0.7\%) and the others $(1.5 \%)$. The estimation of WTP is shown in Table 3, with 95\% confidence level and 5.93\% confidence interval. The five-year value applying the median WTP is estimated to be $128,700,000$ USD $(3,797,500,000$ TWD), which is applied as the maximum budget allowed in Plan B and D. The WTP estimate appears large Taiwanese people deeming Daxi togan as cultural heritage; they are willing to support the government in solving this problem.

Table 3. The estimation of WTP for C1-Cost in Plan B and D.

\begin{tabular}{cccc}
\hline Item & Name & Description & Volume \\
\hline 1 & Number of questionnaire & Responded in total & 272 \\
2 & Mean WTP/household & Willingness to pay (WTP) derived through & Payment Card Method \\
& Median WTP/household & Willingness to pay (WTP) derived through & 371.3 TWD, 12.59 USD \\
3 & Payment Card Method & 122.5 TWD, 4.15 USD \\
4 & Number of households & Total households of taxpayers in Taiwan & $6,200,000$ \\
5 & Annual value & Apply median WTP for a conservative estimate & $759,500,000$ TWD, 25,740,000 USD \\
6 & 5 years value & The maximum allowed budget for Plan B and D & $3,797,500,000$ TWD, 128,700,000 USD \\
\hline \multicolumn{2}{c}{ Note: With 95\% confidence level and 5.93\% confidence interval. }
\end{tabular}

The other part of scenario forecasting explores the relationship between sales and price for estimating impact of Plans D and E on the market. The second WTP (with mean WTP), also applying payment card method, is estimated so as to find the maximum acceptable price increase, as shown in Figure 7. The maximum increase in price consumers are willing to pay for Daxi togan is 109\%. With this figure the market change (i.e., sales) caused by the implementation of Plan D and Plan E can be respectively estimated, and, more importantly, it shows that expensive prices can drastically reduce sales. Even with its superior reputation, Daxi togan cannot win against similar products if the price is uncompetitive. 


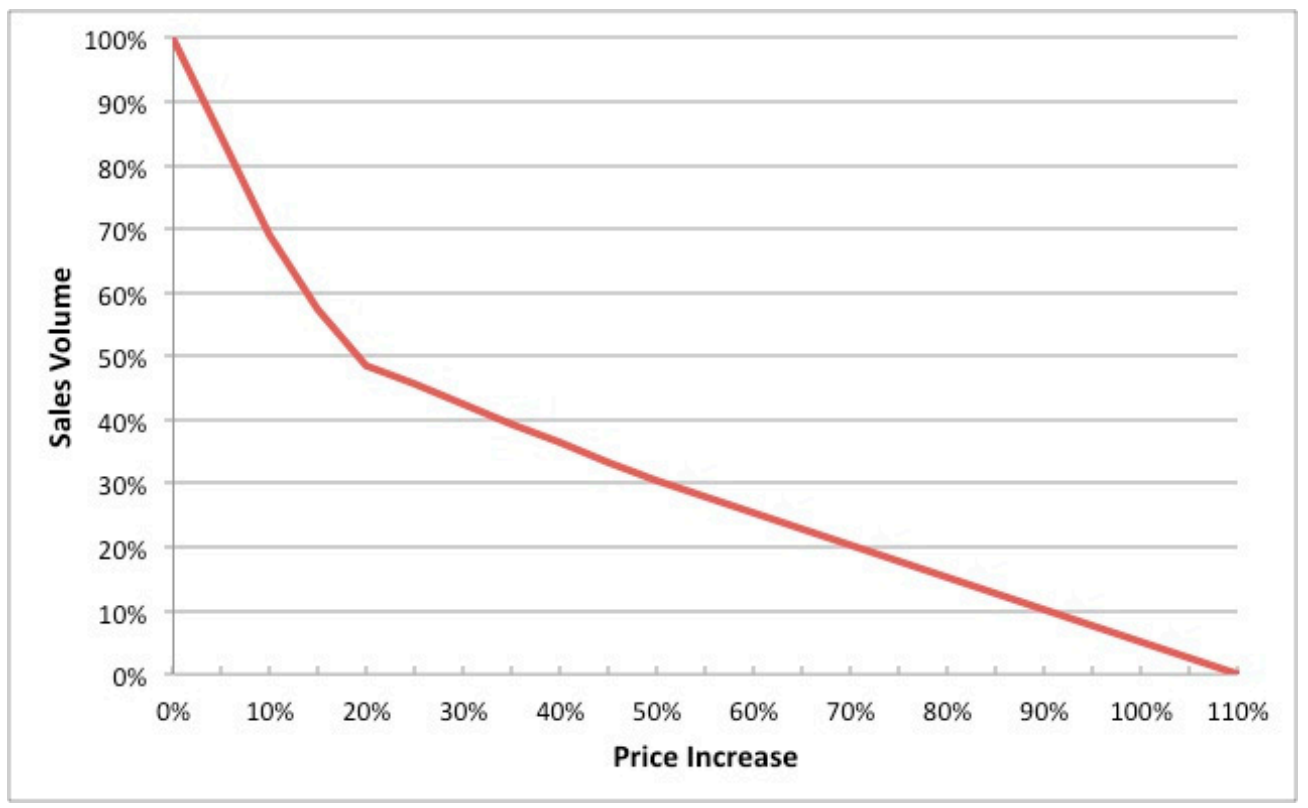

Figure 7. The relationship of sales volume and price, for the scoring of Plan D and E.

After the two critical unknowns are estimated, technical details of the plans can be proposed, such as which waterways to target, the amount of wastewater to treat, treatment capability and the means of economic subsidy, which means that determination of the cost of the five plans can be completed (i.e., the scores of $\mathrm{C} 1$ criterion). Water quality $\mathrm{C} 2$ can be calculated according to $\mathrm{C} 1$ and the technical details. With an estimation of relationship between sales and price, C3 sales can be calculated accordingly; additional costs required from the polluters form the technical details. The scores of $\mathrm{C} 1$, $\mathrm{C} 2$ and $\mathrm{C} 3$ are mainly worked out by the planners, becoming referential information for stakeholders and their representative experts to elicit scoring in C4, C5 and C6 (Table 4). The scoring of C4, C5 and C6 relies on qualitative assessment, initially set ranging from 0 to 10; the experts need to help stakeholders score them according to impacts from the proposed plans. C4-Employment may be affected by the ban of illegal factories, as well as decreases in sales. C5-Heritage Sustainability involves mostly the future loss of reputation due to efforts made by polluters. C6-Heritage Resilience represents recovery from potential loss, for instance, undesirable policy in resource allocation making consumers avoid purchase, or a changed political circumstance forcing the authority to apply legal force.

Table 4. Raw values/scores of the alternatives.

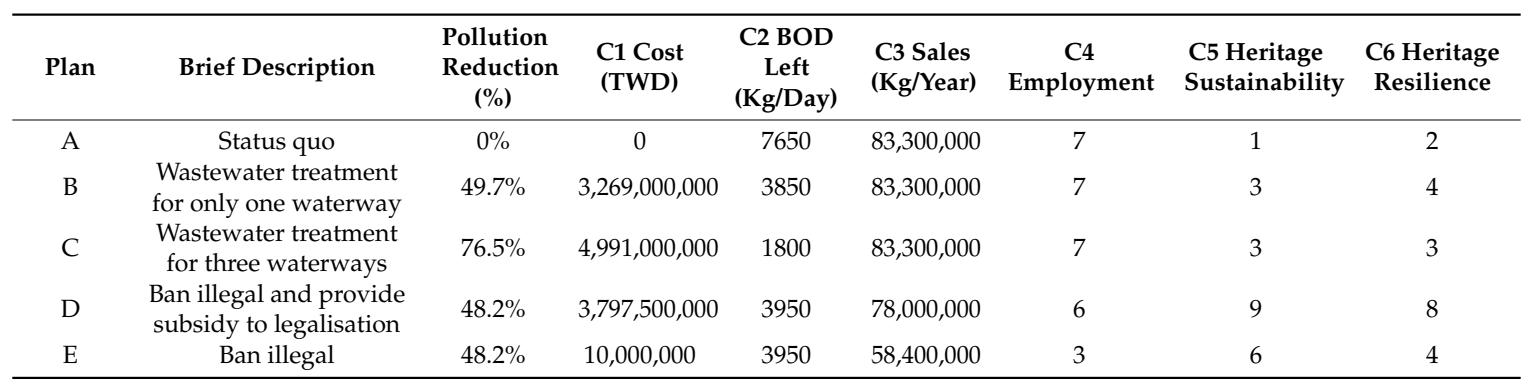

Since Plan B is designed with consideration of the opinion of taxpayers (i.e., WTP) regarding legitimacy of resource allocation, the budget must not exceed 128,700,000 USD (3,797,500,000 TWD). Estimation of cost hence starts from the most polluted waterway-Yuanshulin drainage (YSL) - with an advanced secondary sewage treatment planned to treat 35,000 CMD polluted water. The construction cost is estimated at $1186.4 \mathrm{USD} / \mathrm{CMD}$ and the operation cost $0.169 \mathrm{USD} / \mathrm{M}^{3}$ (according to the average cost of sewage treatment facilities built in Taiwan), overall costs for a twenty-year operation is 
estimated at 3,269,000,000 TWD (110,800,000 USD), within the budget (WTP) of 3,797,500,000 TWD $(128,700,000$ USD).

Plan D is also designed to follow budget constraint (WTP). It proposes banning illegal factories but providing a subsidy for legalisation ( 9.1 TWD per kilogram of togan). Polluter would pay the cost of wastewater treatment, estimated at 2.5 TWD per kilogram of togan (0.085 USD) and assumed to reflect a $2.06 \%$ increase in price. Impact on the sales can be assessed by using Figure 7 , calculated as 78,000,000 Kg/year in C3-Sales (see Table 4). As to the BOD pollution level, it is assumed that after implementation all togan wastewater in the three most polluted waterways is eliminated, any pollution left in the seven waterways would be domestic wastewater.

Plan E also involves the change of price and sales. The score of 58,400,000 Kg/year in C3-Sales (see Table 4) can be calculated through the sum of the cost of legalisation (9.1 TWD per kilogram of togan) and the cost of wastewater treatment (2.5 TWD per kilogram of togan), to be paid by the manufacturers. In terms of government spend, the cost of banning illegal factories is relatively negligible, a significant advantage of the plan with respect to MCDA ranking. As to the BOD pollution level after implementation, it applies the same assumption as Plan D and achieves the same BOD level.

Plan $C$ is proposed as an environment-oriented solution, intercepting and treating polluted water without considering the opinion of the public regarding the legitimacy of resource allocation. Even without knowing the opinion of the public, it is worth consideration as environmental concern can take precedence if pollution levels become dangerous; also, spending money can be simpler than reaching public consensus on resource allocation. Following the estimation of cost for treating the YSL waterway in Plan B, this plan also includes treatment of the second and third most polluted waterways-Puding drainage (PD) and Daxi drainage (DX) — with two basic secondary sewage treatments to treat 35,000 CMD polluted water of each waterway. Construction cost is estimated at 338.9 USD/CMD and the operation cost $0.068 \mathrm{USD} / \mathrm{M}^{3}$ (according to the average cost of sewage treatment facilities built in Taiwan), overall cost for the twenty-year operation is estimated to be $4,991,000,000$ TWD $(169,200,000$ USD), which exceeds the maximum budget (from the estimation of WTP) of 3,797,500,000 TWD (128,700,000 USD). Treatment of the three most polluted waterways can reduce $76.5 \%$ BOD pollution, which is the best performance in terms of river purification amongst these five plans.

After completing the scoring (Table 4), the next step is weighting. Since interest groups are prone to intentionally affect the ranking result in weighting process after seeing the scores, the research suggests using experts to represent the interest/consideration of these conflicting stakeholders, so as to logically and efficiently obtain the weights, as shown in Table 5. This step also comprises of checking whether the set of weights are logical by comparison with the pre-weighting. Instead of scoring and weighting at the same time, such as AHP method, this method highlights the advantage of weighting after scoring, as different scoring results inevitably affect people's elicitation of the weights. For instance, if all the raw scores of C2-BOD of the five plans become only $10 \%$ of the current volume, although scores after standardisation will still be the same, the importance of C2-BOD is actually different, implying the set of weights should all be altered. In other words, in MCDA, the scale of the raw scores of criterion is critical, as the weighted sum method reflects the overall performance from the ratio relations between scores.

Table 5. Weighting of the three experts representing the conflicting stakeholder groups.

\begin{tabular}{ccccccc}
\hline & C1 Cost & C2 BOD Left & C3 Sales & $\begin{array}{c}\text { C4 } \\
\text { Employment }\end{array}$ & $\begin{array}{c}\text { C5 Heritage } \\
\text { Sustainability }\end{array}$ & $\begin{array}{c}\text { C6 Heritage } \\
\text { Resilience }\end{array}$ \\
\hline Environment & 0.18 & 0.31 & 0.16 & 0.06 & 0.15 & 0.14 \\
Heritage & 0.13 & 0.16 & 0.24 & 0.10 & 0.19 & 0.18 \\
Planning & 0.23 & 0.28 & 0.20 & 0.08 & 0.11 & 0.10 \\
Mean & 0.18 & 0.25 & 0.20 & 0.08 & 0.15 & 0.14 \\
\hline
\end{tabular}


The next step is standardising these raw scores. The MCDA research carried out two ways of scaling, as shown in Table 6. Global scaling is a linear transformation using maximum and minimum 'possible' values assigned for each criterion as upper and lower boundaries, whilst local scaling is a linear transformation using the maximum and minimum 'measured' values (i.e., scores) for each criterion as upper and lower boundaries (for details of the two methods please see [59]). Taking C3 as an example (Table 4) for global scaling, the score 7650 of Plan A is the maximum possible value and will be calculated as the upper boundary 100; and the minimum possible value is 0 rather than the score 1800 of Plan C, which will be calculated as the lower boundary 0 . Whilst for local scaling, the score 7650 of Plan A is the maximum measured value and will be calculated as the upper boundary 100; and the score 1800 of Plan $C$ is the minimum measured value and will be calculated as the lower boundary 0 . As to qualitative criteria, since the scoring of $\mathrm{C} 4, \mathrm{C} 5$ and $\mathrm{C} 6$ is initially set ranging from 0 to 10, which facilitates the transformation of global scaling, as the maximum (100) and minimum (0) possible values are relatively of the same scale. As different scaling methods sometimes lead to different ranking results, scaling methods must be used appropriately if the logical results are to be obtained [59]. After calculating the overall preference Pi with the Equation (1) using the set of mean weights (Table 5), the results of ranking from the two scaling methods show the difference (Table 6). The main difference in order is Plan E, which reveals that a minimum score of 0 in C3-Sales of the local scaling disproportionately represents the ratio relation of raw scores, leading to a drop from second position to fourth. Generally the local scaling performs better than the global only when most of the limitations/boundaries of the ranges happen to be the minimums and maximums of raw scores of criteria. In addition, global scaling is more appropriate for qualitative criteria due to the consistency between raw scores and standardised scores, as in the aforementioned example, where the local scaling apparently results in distortion. Therefore, the research intends to make the point that the selection of scaling method depends on the nature of the case given and it should be transparent to stakeholder participation in the MCDA proposed.

Table 6. Standardised scores of the alternatives (the more the better), with global scaling and local scaling.

\begin{tabular}{|c|c|c|c|c|c|c|c|c|}
\hline \multicolumn{9}{|c|}{ Global Scaling } \\
\hline Plan & C1 Cost & C2 BOD Left & C3 Sales & $\begin{array}{c}\text { C4 } \\
\text { Employment }\end{array}$ & $\begin{array}{c}\text { C5 Heritage } \\
\text { Sustainability }\end{array}$ & $\begin{array}{l}\text { C6 Heritage } \\
\text { Resilience }\end{array}$ & Overall Value & Ranking \\
\hline $\mathrm{A}$ & 100.00 & 0.00 & 100.00 & 70.00 & 10.00 & 20.00 & 47.90 & 5 \\
\hline $\mathrm{B}$ & 45.52 & 49.66 & 100.00 & 70.00 & 30.00 & 40.00 & 56.31 & 4 \\
\hline $\mathrm{C}$ & 16.82 & 76.45 & 100.00 & 70.00 & 30.00 & 30.00 & 56.44 & 3 \\
\hline $\mathrm{D}$ & 36.71 & 48.22 & 93.61 & 60.00 & 90.00 & 80.00 & 66.89 & 1 \\
\hline $\mathrm{E}$ & 99.83 & 48.22 & 70.05 & 30.00 & 60.00 & 40.00 & 61.04 & 2 \\
\hline \multicolumn{9}{|c|}{ Local Scaling } \\
\hline Plan & C1 Cost & C2 BOD Left & C3 Sales & $\begin{array}{c}\text { C4 } \\
\text { Employment }\end{array}$ & $\begin{array}{c}\text { C5 Heritage } \\
\text { Sustainability }\end{array}$ & $\begin{array}{l}\text { C6 Heritage } \\
\text { Resilience }\end{array}$ & Overall Value & Ranking \\
\hline $\mathrm{A}$ & 100.00 & 0.00 & 100.00 & 100.00 & 0.00 & 0.00 & 46.00 & 5 \\
\hline B & 34.50 & 64.96 & 100.00 & 100.00 & 25.00 & 33.33 & 58.87 & 3 \\
\hline $\mathrm{C}$ & 0.00 & 100.00 & 100.00 & 100.00 & 25.00 & 16.67 & 59.08 & 2 \\
\hline $\mathrm{D}$ & 23.91 & 63.07 & 78.67 & 75.00 & 100.00 & 100.00 & 70.81 & 1 \\
\hline $\mathrm{E}$ & 99.80 & 63.07 & 0.00 & 0.00 & 62.50 & 33.33 & 47.77 & 4 \\
\hline
\end{tabular}

The final result that applies global scaling from Table 6 is shown as Figures 8 and 9. Generally speaking, the top rank is Plan D, followed by Plan E; the order between Plan B and Plan C are relatively sensitive and unstable; Plan A (i.e., status quo) robustly places last. A different order can be seen from the ranking of the planning expert, with a relatively high weight of 0.23 of C1-Cost (Table 5), that Plan E outranks Plan D due to having outstanding performance in cost and that Plan B outranks Plan C for the same reason. It reveals that the decision-maker should notice the possibility of order changing for instance if the government faces high financial pressure. Consequently, we conduct a sensitivity analysis targeting this critical criterion, as shown in Table 5 and Figure 10, if the applied weight of C1-Cost is raised (currently 0.18 , see Table 5), with the rest of the criteria lowered proportionately, 
Plan D will only remain at the top rank until approximately 0.24 and then be outranked by Plan E, which reveals the sensitive character of the cost criterion amongst the alternatives.

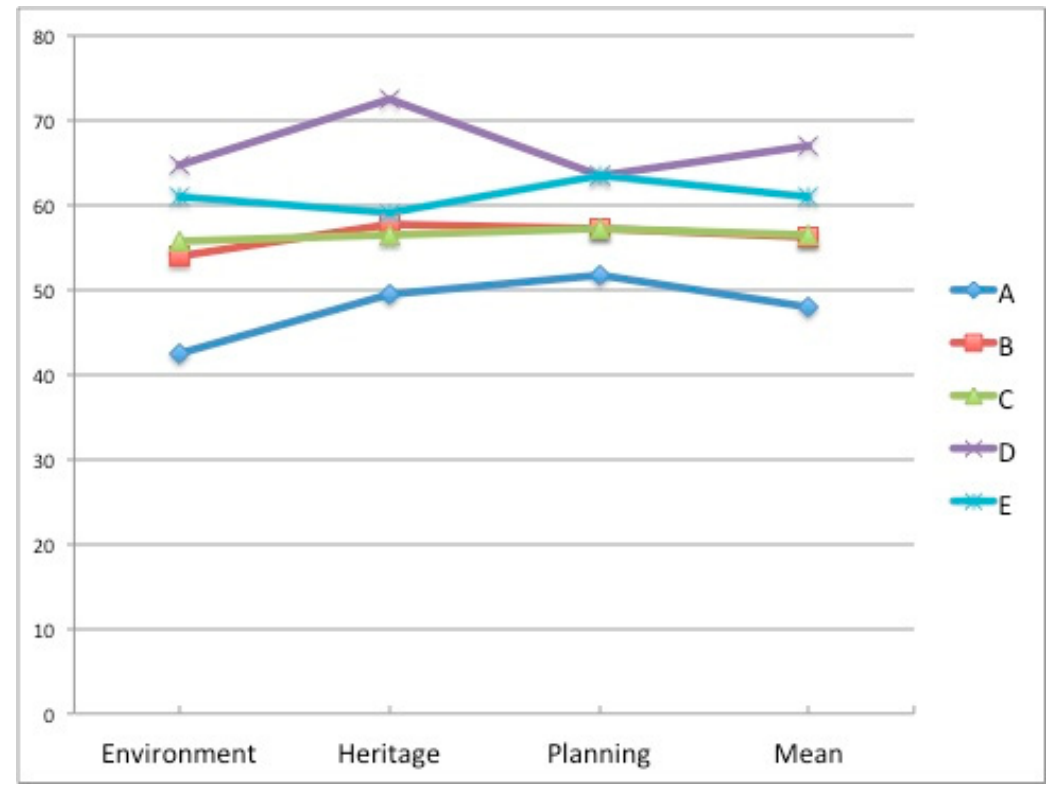

Figure 8. Overall preference of the alternatives from the three experts.

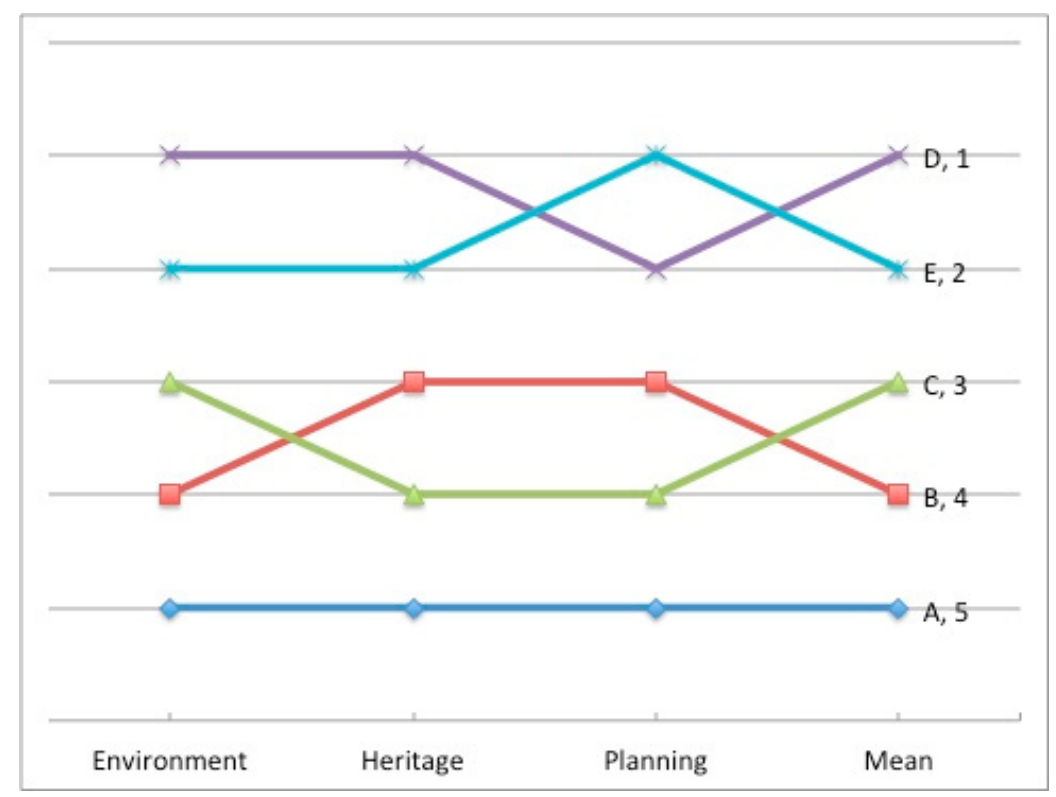

Figure 9. Overall ranking order of the alternatives from the three experts.

As the pollution level of the seven waterways will increase with the development of the togan industry, the later a resolution is found and implemented, the worse the situation will become. This suggests that the weight of criterion regarding environment would very likely be higher in the future. Therefore, another sensitivity analysis is carried out, as shown in Figure 11; if the weight of C2-BOD is raised (current 0.25 , see Table 5), with the rest of the criteria lowered proportionately, Plan D will hold top rank until approximately 0.45 and then be outranked by Plan C, which reveals the robustness of the environment criterion amongst the alternatives. These two sensitivity analyses provide the decision maker with the important information that Plan D is robust at the top rank in terms of criteria weights; and the government do not need to worry about the possibility of order changing regarding the environment criterion but financial circumstances can cause change. 
Since the information shows C1-Cost can affect Plan D's top ranking, there is a requirement to see if Plan D can be improved. The research wants to know whether this can be achieved by adjusting the score. An adjustment of Plan D to reduce the cost has been tried, which comes with some criteria scores changed in C3-Sales and C6-Heritage Resilience. The new overall preference is consequently advanced from 66.89 (see Table 4) to 67.38 (Table 7), which also makes the gap bigger between the first rank and the second. The sensitivity analysis demonstrates a way for adjusting and improving the preferred plan, so that it is more practicable and advantageous to the decision maker, as the implementation stage (e.g., developing action plan) will inevitably encounter some unpredictable challenges or assessment deviation that makes the adjustment necessary.

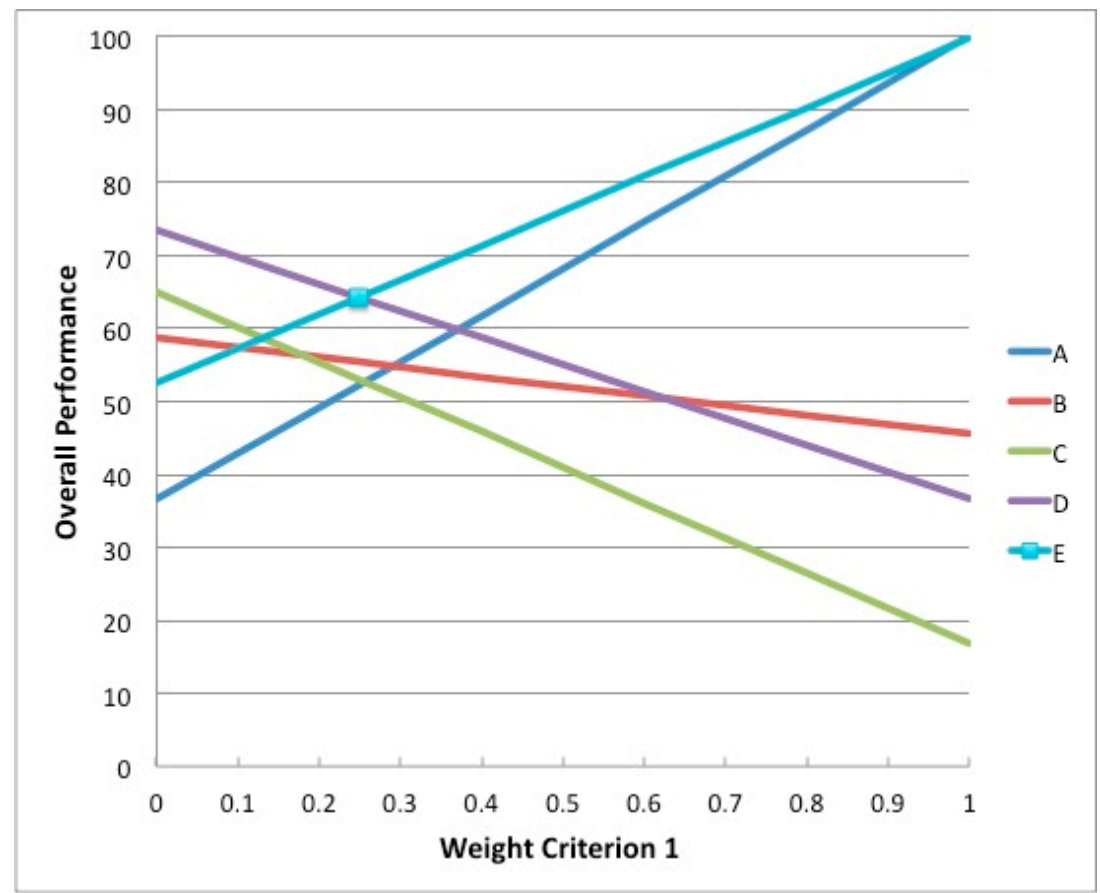

Figure 10. Sensitivity analysis targeting the weight of C1.

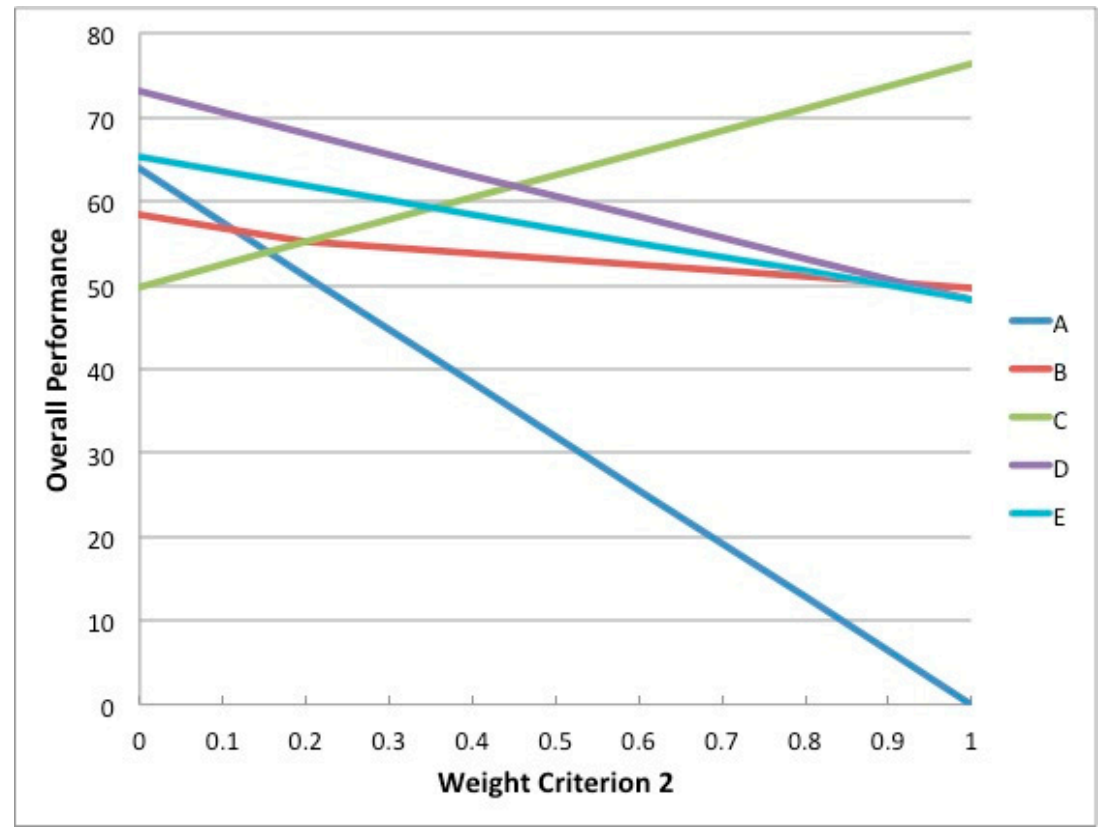

Figure 11. Sensitivity analysis targeting the weight of C2. 
Table 7. The analsis after adjusting the cost/budget of Plan D.

\begin{tabular}{|c|c|c|c|c|c|c|c|c|}
\hline Plan & C1 Cost & $\begin{array}{c}\text { C2 BOD } \\
\text { Left }\end{array}$ & C3 Sales & $\begin{array}{c}\text { C4 } \\
\text { Employment }\end{array}$ & $\begin{array}{c}\text { C5 Heritage } \\
\text { Sustainability }\end{array}$ & $\begin{array}{l}\text { C6 Heritage } \\
\text { Resilience }\end{array}$ & $\begin{array}{l}\text { Overall } \\
\text { Value }\end{array}$ & Ranking \\
\hline $\mathrm{A}$ & 0 & 7650 & $83,300,000$ & 7 & 1 & 2 & 47.90 & 5 \\
\hline B & $3,269,000,000$ & 3850 & $83,300,000$ & 7 & 3 & 4 & 56.31 & 4 \\
\hline $\mathrm{C}$ & $4,991,000,000$ & 1800 & $83,300,000$ & 7 & 3 & 3 & 56.44 & 3 \\
\hline $\mathrm{D}$ & $1,900,000,000$ * & 3950 & $68,000,000 *$ & 6 & 9 & $6^{*}$ & $67.38 *$ & 1 \\
\hline $\mathrm{E}$ & $10,000,000$ & 3950 & $58,400,000$ & 3 & 6 & 4 & 61.04 & 2 \\
\hline
\end{tabular}

\section{Conclusions}

Existing literature concerning MCDA is still scarce in considering how it can be enhanced by drawing on methods and practice from other disciplines. Whilst the results of the research provide insight into the integration of scenario forecasting (i.e., CVM) and MCDA, the primary objective of this paper is to provide a practical recommendation for tackling the complex environmental problem of Daxi, where a cultural heritage and the natural environment, both of which are considered worth protection (with WTP estimate of 128,700,000 USD from the public), are at odds with each other. The preferred plan applies multiple policy instruments-regulatory instrument used to ban polluting discharge, economic instrument utilised to subsidise the legalisation of the polluters-and still follows polluter-pays principle regarding the treatment costs. The finding is that the recognition of the cultural heritage of Daxi indeed affects the selection of policy instruments, shifting from an absolute polluter-pays principle to a softer status mixed with the government-pays basis. The estimation towards the changes in sales and market caused by policy implementation also shows the demand for and advantage of scenario forecasting in MCDA and decision-making support in the future. Also, importantly, the proposed MCDA highlights its participatory feature supported by key steps, in particular the intervention prospective, the scenario forecasting and the sensitivity analysis. The method of employing WTP to obtain the relationship between sales and price does require room to improve, yet the attempt may be of value in stimulating more discussion on wider application of CVM. In addition, notwithstanding the analysis can be a reference for local government with regards to the solution of this complex environmental problem, a new WTP survey officially conducted by the government with more responses (e.g., lower confidence interval) and better representativeness (e.g., the distribution of respondents) of questionnaire is recommended. A more thoroughly informed survey, with more government instruments supported as well as a better statistic assessment, can considerably benefit the performance of policy decision-making, particularly involving resource allocation and social justice.

Author Contributions: Writing-Original Draft Preparation, O.C.; Supervision, D.H.

Funding: This work was supported by the Institutional Links grant [332430681] under the Newton-Mosharafa Fund. The grant is funded by the UK Department of Business, Energy and Industrial Strategy (BEIS) and Egypt Science and Technology Development Fund (STDF) and delivered by the British Council. For further information, please visit www.newtonfund.ac.uk.

Acknowledgments: Sincere gratitude to MWH Taiwan branch (in particular Jacky Tung) for the support with the data of the water sampling; the authors are also grateful to all the respondents of the survey for their helpful contributions.

Conflicts of Interest: The authors declare no conflict of interest.

\section{Appendix A. Economic Valuation Questionnaire}

Daxi is a historic town of Taoyuan City in northern Taiwan, which was voted as the number one hot spot of 'the top 10 small tourist towns of Taiwan' in 2012. The town is popular in tourism due to abundant tourist attractions of cultural heritage and scenery spots. The town covers the main part of two water resource conservation areas, namely Shihmen Reservoir and Bansin water resource conservation area, which is considered one of the most important water resource area and catchment in 
Taiwan. Excellent water quality and nature conditions have made Daxi famous for tea production since late 18 century, as well as the centenary historic togan production. Plus abundant cultural heritage, including the Daxi Old Street, the Lee Teng-fan's Ancient Residence, Japanese historical architecture Daxi Wude Hall, Daxi Furen Temple, Cihu Mausoleum and Touliao Mausoleum, the significance of culture and tourism of Daxi has been recognised by Taiwanese people.

Q 10. Next, please imagine the situation described below.

The production of Daxi togan has caused an increasing concern of pollution to water resource that supplies tap water to most of the area of New Taipei city and Taoyuan City, whilst the development of togan production has its historical background, meaning the responsibility for pollution is not exactly the fault of the manufacturers. Since togan has become an essential part of cultural heritage of Daxi, as well as an important industry, the local government plans to tackle the pollution problem whilst also maintain the sustainability of the development of the togan industry. Given the difficulty in financial condition of the local government, the funds for the plan would be collected as a tax for five years from all households in Taiwan.

What, in your honest opinion, would be a reasonable maximum amount of annual tax your household would be prepared to pay in the five years to deal with the water pollution issue from Daxi, as well as to improve the sustainable development of the Daxi togan industry?

When answering about your household's willingness to pay for the conduct of the resolution, remember that you may prefer to use money for some other project, for example, health care or some other project related to the environment of Taiwan.

Please, select only one of the following alternatives.

Annual tax (TWD) for your household:

\begin{tabular}{ccccccccccccccc}
\hline$\$ 0$ & $\$ 5$ & $\$ 15$ & $\$ 30$ & $\$ 50$ & $\$ 75$ & $\$ 105$ & $\$ 140$ & $\$ 180$ & $\$ 225$ & $\$ 270$ & $\$ 350$ & $\$ 500$ & $\$ 800$ & More than $\$ 1300$ \\
\hline$\square$ & $\square$ & $\square$ & $\square$ & $\square$ & $\square$ & $\square$ & $\square$ & $\square$ & $\square$ & $\square$ & $\square$ & $\square$ & $\square$ & $\begin{array}{c}\text { Specified } \\
\text { amount: }\end{array}$ \\
\hline
\end{tabular}

Next, please imagine 5 situations described below. Assuming your family buys 10 bags of Daxi togan every year,

Q 11. how many bags will you buy if the price of Daxi togan is raised from 50 to 55 TWD per bag (10\% increase)?

Q 12. how many bags will you buy if the price of Daxi togan is raised from 50 to 57.5 TWD per bag (15\% increase)?

Q 13. how many bags will you buy if the price of Daxi togan is raised from 50 to 60 TWD per bag (20\% increase)?

Q 14. how many bags will you buy if the price of Daxi togan is raised from 50 to 75 TWD per bag (50\% increase)?

Q 15. how much money per bag are you willing to pay at most for Daxi togan, instead of turning to buy the togan produced by other areas of Taiwan?

\begin{tabular}{cccccccc}
\hline$\$ 80$ & $\$ 90$ & $\$ 100$ & $\$ 115$ & $\$ 130$ & $\$ 150$ & $\$ 175$ & More than $\$ 200$ \\
\hline$\square$ & $\square$ & $\square$ & $\square$ & $\square$ & $\square$ & $\square$ & Specified price: \\
\hline
\end{tabular}

\section{References}

1. Belton, V.; Stewart, T. Multiple Criteria Decision Analysis: An Integrated Approach; Springer Science \& Business Media: Boston, MA, USA, 2002.

2. Kiker, G.A.; Bridges, T.S.; Varghese, A.; Seager, T.P.; Linkov, I. Application of multicriteria decision analysis in environmental decision making. Integr. Environ. Assess. Manag. 2005, 1, 95-108. [CrossRef] [PubMed] 
3. Xidonas, P.; Mavrotas, G.; Zopounidis, C.; Psarras, J. IPSSIS: An integrated multicriteria decision support system for equity portfolio construction and selection. Eur. J. Oper. Res. 2011, 210, 398-409. [CrossRef]

4. Ferretti, V.; Bottero, M.; Mondini, G. Decision making and cultural heritage: An application of the multi-attribute value theory for the reuse of historical buildings. J. Cult. Herit. 2014, 15, 644-655. [CrossRef]

5. Ferretti, V.; Comino, E. An integrated framework to assess complex cultural and natural heritage systems with multi-attribute value theory. J. Cult. Herit. 2015, 16, 688-697. [CrossRef]

6. Oliveira, A.S.; de Barros, M.D.; de Carvalho Pereira, F.; Gomes, C.F.S.; da Costa, H.G. Prospective scenarios: A literature review on the scopus database. Futures 2018, 100, 20-33. [CrossRef]

7. Gomes, C.F.S.; Costa, H.G. Using prospective vision and multi-criteria decision analysis with scenario planning. Relat. Pesqui. Eng. Prod. 2013, 13, 94-114.

8. Kowalski, K.; Stagl, S.; Madlener, R.; Omann, I. Sustainable energy futures: Methodological challenges in combining scenarios and participatory multi-criteria analysis. Eur. J. Oper. Res. 2009, 197, 1063-1074. [CrossRef]

9. Lehtoranta, V.; Seppälä, E.; Kosenius, A.-K. Willingness to pay for water level regulation in Lake Pielinen, Finland. J. Environ. Econ. Policy 2013, 2, 148-163. [CrossRef]

10. Daron, J.D.; Colenbrander, D.R. A critical investigation of evaluation matrices to inform coastal adaptation and planning decisions at the local scale. J. Environ. Plan. Manag. 2015, 58, 2250-2270. [CrossRef]

11. Turpie, J.; Mander, M.; Joubert, A. Framework and Methodology for Incorporation of Economics into Resource Directed Measures and the Strategic Adaptive Management of Water Resources in South Africa; Institute of Natural Resources Discussion Paper; Water Research Commission: Pretoria, South Africa, 2000.

12. Zoppi, C. A multicriteria-contingent valuation analysis concerning a coastal area of Sardinia, Italy. Land Use Policy 2007, 24, 322-337. [CrossRef]

13. Thórhallsdóttir, T.E. Environment and energy in Iceland: A comparative analysis of values and impacts. Environ. Impact Assess. Rev. 2007, 27, 522-544. [CrossRef]

14. Giove, S.; Rosato, P.; Breil, M. An application of multicriteria decision making to built heritage. The redevelopment of Venice Arsenale. J. Multi-Criteria Decis. Anal. 2010, 17, 85-99. [CrossRef]

15. Di Bitonto, P.; Laterza, M.; Roselli, T.; Rossano, V. Multi-criteria retrieval in cultural heritage recommendation systems. In Proceedings of the International Conference on Knowledge-Based and Intelligent Information and Engineering Systems, Cardiff, UK, 8-10 September 2010; Springer: Berlin/Heidelberg, Germany, 2010; pp. 64-73.

16. Fuentes, J.M. Methodological bases for documenting and reusing vernacular farm architecture. J. Cult. Herit. 2010, 11, 119-129. [CrossRef]

17. Dutta, M.; Husain, Z. An application of multicriteria decision making to built heritage. The case of Calcutta. J. Cult. Herit. 2009, 10, 237-243. [CrossRef]

18. Hamadouche, M.; Mederbal, K.; Kouri, L.; Regagba, Z.; Fekir, Y.; Anteur, D. GIS-based multicriteria analysis: An approach to select priority areas for preservation in the Ahaggar National Park, Algeria. Arab. J. Geosci. 2014, 7, 419-434. [CrossRef]

19. Palmas, C.; Abis, E.; von Haaren, C.; Lovett, A. Renewables in residential development: An integrated GIS-based multicriteria approach for decentralized micro-renewable energy production in new settlement development: A case study of the eastern metropolitan area of Cagliari, Sardinia, Italy. Energy Sustain. Soc. 2012, 2, 10. [CrossRef]

20. Paolillo, P.L.; Benedetti, A.; Baresi, U.; Terlizzi, L.; Graj, G. An assessment-based process for modifying the built fabric of historic centres: The case of Como in Lombardy. In Proceedings of the International Conference on Computational Science and Its Applications, Santander, Spain, 20-23 June 2011; Springer: Berlin/Heidelberg, Germany, 2011; pp. 162-176.

21. Tarragüel, A.A.; Krol, B.; Van Westen, C. Analysing the possible impact of landslides and avalanches on cultural heritage in Upper Svaneti, Georgia. J. Cult. Herit. 2012, 13, 453-461. [CrossRef]

22. Cerreta, M.; Panaro, S.; Cannatella, D. Multidimensional spatial decision-making process: Local shared values in action. In Proceedings of the International Conference on Computational Science and Its Applications, Salvador de Bahia, Brazil, 18-21 June 2012; Springer: Berlin/Heidelberg, Germany, 2012; pp. 54-70.

23. Girard, L.F.; De Toro, P. Integrated spatial assessment: A multicriteria approach to sustainable development of cultural and environmental heritage in San Marco dei Cavoti, Italy. Cent. Eur. J. Oper. Res. 2007, 15, 281-299. [CrossRef] 
24. Bryan, B.A.; Grandgirard, A.; Ward, J.R. Quantifying and exploring strategic regional priorities for managing natural capital and ecosystem services given multiple stakeholder perspectives. Ecosystems 2010, 13, 539-555. [CrossRef]

25. Wang, H.-J.; Zeng, Z.-T. A multi-objective decision-making process for reuse selection of historic buildings. Expert Syst. Appl. 2010, 37, 1241-1249. [CrossRef]

26. Patiwael, P.R.; Groote, P.; Vanclay, F. Improving heritage impact assessment: An analytical critique of the ICOMOS guidelines. Int. J. Herit. Stud. 2018, 1-15. [CrossRef]

27. Walter, N. From values to narrative: A new foundation for the conservation of historic buildings. Int. J. Herit. Stud. 2014, 20, 634-650. [CrossRef]

28. Jokilehto, J. History of Architectural Conservation; Routledge: London, UK, 2007.

29. Smith, L. Uses of Heritage; Routledge, Taylor \& Francis Group: London, UK, 2006; p. xiv. 351p.

30. Waterton, E.; Smith, L. Heritage protection for the 21st century. Cult. Trends 2008, 17, 197-203. [CrossRef]

31. Ashworth, G. Preservation, conservation and heritage: Approaches to the past in the present through the built environment. Asian Anthropol. 2011, 10, 1-18. [CrossRef]

32. Byrne, D.; Brayshaw, H.; Ireland, T. Social Significance: A Discussion Paper; NSW National Parks and Wildlife Service: Hurstville, Australia, 2003.

33. The transformation of the daxi togan industry: More than 10 billion annual sales value. Epoch Times, 4 April 2007.

34. Montgomery, D.R.; Huang, M.Y.-F.; Huang, A.Y.-L. Regional soil erosion in response to land use and increased typhoon frequency and intensity, Taiwan. Quat. Res. 2014, 81, 15-20. [CrossRef]

35. Fishburn, P.C. Letter to the editor-Additive utilities with incomplete product sets: Application to priorities and assignments. Oper. Res. 1967, 15, 537-542. [CrossRef]

36. Bronstein, D.A.V. Environmental and Social Impact Assessment; J. Wiley: Hoboken, NJ, USA, 1995.

37. Vanclay, F. International principles for social impact assessment. Impact Assess. Proj. Apprais. 2003, $21,5-12$. [CrossRef]

38. Le Galès, P. Policy Instruments and Governance; Sage: London, UK, 2011.

39. Pearce, D.W. The Polluter Pays Principle; Environmental Economics Centre, International Institute for Environment and Development: London, UK, 1989.

40. Howlett, M. Policy instruments, policy styles, and policy implementation: National approaches to theories of instrument choice. Policy Stud. J. 1991, 19, 1-21. [CrossRef]

41. Bemelmans-Videc, M.-L.; Rist, R.C.; Vedung, E.O. Carrots, Sticks, and Sermons: Policy Instruments and Their Evaluation; Transaction Publishers: Piscataway, NJ, USA, 2011; Volume 1.

42. Hood, C.C.; Margetts, H.Z. The Tools of Government in the Digital Age; Palgrave Macmillan: Basingstoke, UK, 2007.

43. Jordan, A.; Wurzel, R.K.; Zito, A. The rise of 'new'policy instruments in comparative perspective: Has governance eclipsed government? Political Stud. 2005, 53, 477-496. [CrossRef]

44. Linder, S.H.; Peters, B.G. Instruments of government: Perceptions and contexts. J. Public Policy 1989, 9, 35-58. [CrossRef]

45. Lester, S.M. The Tools of Government. A Guide to the New Governance; Oxford University Press: New York, NY, USA, 2002.

46. Bateman, I.J.; Carson, R.T.; Day, B.; Hanemann, M.; Hanley, N.; Hett, T.; Jones-Lee, M.; Loomes, G.; Mourato, S.; Pearce, D. Economic Valuation with Stated Preference Techniques: A Manual; Edward Elgar: Cheltenham, UK, 2002.

47. Boyle, K.J. Contingent valuation in practice. In A Primer on Nonmarket Valuation; Springer: Dordrecht, The Netherlands, 2003; pp. 111-169.

48. Johnston, R.J.; Boyle, K.J.; Adamowicz, W.; Bennett, J.; Brouwer, R.; Cameron, T.A.; Hanemann, W.M.; Hanley, N.; Ryan, M.; Scarpa, R. Contemporary guidance for stated preference studies. J. Assoc. Environ. Resour. Econ. 2017, 4, 319-405. [CrossRef]

49. Mitchell, R.C.; Carson, R.T. Using Surveys to Value Public Goods: The Contingent Valuation Method; Taylor and Francis: Hoboken, NJ, USA, 2013.

50. Cameron, T.A.; Huppert, D.D. OLS versus $\mathrm{ml}$ estimation of non-market resource values with payment card interval data. J. Environ. Econ. Manag. 1989, 17, 230-246. [CrossRef] 
51. Hackl, F.; Pruckner, G.J. On the gap between payment card and closed-ended CVM-answers. Appl. Econ. 1999, 31, 733-742. [CrossRef]

52. Champ, P.A.; Bishop, R.C. Is willingness to pay for a public good sensitive to the elicitation format? Land Econ. 2006, 82, 162-173. [CrossRef]

53. Thur, S.M. User fees as sustainable financing mechanisms for marine protected areas: An application to the bonaire national marine park. Mar. Policy 2010, 34, 63-69. [CrossRef]

54. Boyle, J. Cultural influences on implementing environmental impact assessment: Insights from Thailand, Indonesia, and Malaysia. Environ. Impact Assess. Rev. 1998, 18, 95-116. [CrossRef]

55. Turnbull, B.W. The empirical distribution function with arbitrarily grouped, censored and truncated data. J. R. Stat. Soc. Ser. B (Methodol.) 1976, 38, 290-295.

56. Blaine, T.W.; Lichtkoppler, F.R.; Jones, K.R.; Zondag, R.H. An assessment of household willingness to pay for curbside recycling: A comparison of payment card and referendum approaches. J. Environ. Manag. 2005, 76, 15-22. [CrossRef]

57. Kriström, B. A non-parametric approach to the estimation of welfare measures in discrete response valuation studies. Land Econ. 1990, 66, 135-139. [CrossRef]

58. Huei-Yann, J.; Chien-Der, L. Embedding effects of contingent valuation method-evidence form evaluating wildlife-protected areas in Taiwan. J. Agric. Econ. 1997, 64, 125-139.

59. Martin, D.; Mazzotta, M. Non-monetary valuation using multi-criteria decision analysis: Sensitivity of additive aggregation methods to scaling and compensation assumptions. Ecosyst. Serv. 2018, 29, 13-22. [CrossRef] [PubMed]

(C) 2018 by the authors. Licensee MDPI, Basel, Switzerland. This article is an open access article distributed under the terms and conditions of the Creative Commons Attribution (CC BY) license (http://creativecommons.org/licenses/by/4.0/). 